\title{
Glanzmann Thrombasthenia: A Case Report in Moroccan Child
}

\author{
Zohair Ait Ouzdi, Fatimazahra Marhoume, Khalil Haouach \\ Department of Hematology, the Mohamed VI University Hospital, Marrakech, Morocco
}

Email address:

aitouzdizohair@gmail.com (Z.A. Ouzdi)

\section{To cite this article:}

Zohair Ait Ouzdi, Fatimazahra Marhoume, Khalil Haouach. Glanzmann Thrombasthenia: A Case Report in Moroccan Child. American Journal of Laboratory Medicine. Vol. 3, No. 5, 2018, pp. 44-47. doi: 10.11648/j.ajlm.20180305.12

Received: October 14, 2018; Accepted: November 1, 2018; Published: November 28, 2018

\begin{abstract}
Glanzmann thrombasthenia is a hereditary hemorrhagic problem and is characterized by a qualitative or quantitative deficiency of the platelet glycoprotein GPIIb-IIIa, responsible for the reduction of platelet aggregation. The reported case concerns an 11-year-old child admitted to the Clinical Hematology Department of the University Hospital Mohamed 6 for epistaxis and gingivorrhagia. The questioning of the father revealed the concept of consanguinity, as well as his history of death and his hemorrhagic syndrome. The biological assessment performed in a patient shows a normal blood count; it is not particularly thrombocytopenia and the platelets have an average volume of $10.6 \mathrm{fL}$, the prothrombin time (PT), the partial thromboplastin time with activator (APTT) are normal. The platelet occlusion time (POT) is lengthened. The von Willebrand factor has not been investigated: the antigen (VWF-Ag) is $148 \%$ and the cofactor of ristocetin (VWF-RCo) is $116 \%$. On the other hand, the exploration of platelet functions shows a lack of aggregation or of the platelet activator used: there is no aggregation in the presence of collagen, ADP, acid arachidonic, and aggregation induced by ristocetin is very disturbed. Immunophenotyping of platelet glycoproteins and the study of glycoprotein expression after thrombin activation by flow cytometry resulting from GpIIbIIIa (CD41), GpIIIa (CD61). The diagnosis is available for this patient is Glanzmann trombasthenia.
\end{abstract}

Keywords: Glanzmann Thrombasthenia, Hemorrhagic Syndrome, Deficiency of Glycoprotein, GP IIb-IIIa

\section{Introduction}

Glanzmann thrombasthenia is a platelet, congenital, autosomal recessive disorder. The absence or marked decrease in platelet aggregation is the main feature of the disease. It is a rare pathology, often encountered in the context of consanguinity [1].

The pathology originates from a quantitative or qualitative deficit of GpIIbIIIa (or integrin alphaIIbbeta3). Thus, there are several types of Glanzmann disease: type 1 characterized by an expression rate of GpIIbIIIa of less than 5\%, clinically manifested by severe bleeding. And type 2 or GpIIbIIIa expression is between 5 and $25 \%$, leading to moderate bleeding episodes [2].

Furthermore, there are also cases of acquired Glanzmann thrombasthenia: it is essentially thrombopathies originating from the presence of an autoantibody directed against GpIIbIIIa detected in the context of Hodgkin's lymphoma [3]. This report describes a case of Glanzmann's thrombasthenia and review the current literature.

\section{Case Report}

This is an 11-year-old child admitted to hematology for the evaluation of recurrent episodes of epistaxis associated with frequent gingivorrhagia and a tendency to bruising since the age of 7 years. The interview of the father reveals the notion of consanguinity of parents who had already had a girl who died at a young age by haemorrhaging. On physical examination his radial pulse was $89 / \mathrm{min}$, regular, and blood pressure: $120 / 75 \mathrm{mmHg}$. The patient was pale and rest of general physical examination was normal. There were no bruises, ecchymosis or purpuric spots on the skin. There was no lymphadenopathy; liver and spleen were not palpable. The rest of the clinical examination was normal.

The biological assessment performed in this patient shows a normal blood count; in particular there is no thrombocytopenia and the platelet morphology was normal (table 1). 
The Prothrombin time (PT), partial thromboplastin time with activator (APTT) is normal. The platelet occlusion time (POT) is lengthened. The von Willebrand factor does not show any abnormality: the antigen (VWF: $\mathrm{Ag}$ ) is $148 \%$ and the cofactor activity of ristocetin (VWF: RCo) is $116 \%$ (table2). On the other hand, the exploration of platelet functions shows a lack of aggregation irrespective of the platelet activator used: there is no aggregation in the presence of collagen, ADP, arachidonic acid, and ristocetin-induced aggregation is highly disturbed (table 3, figure 1). In addition, the factor VIII is greater than $150 \%$ and the factor XIII is $79.4 \%$. Thus the diagnosis for this patient is Glanzmann thrombasthenia. The immunophenotyping of platelet glycoproteins and the study of the expression of glycoproteins after activation by thrombin by flow cytometry show a lack of expression of GpIIbIIIa (CD41), GpIIIa (CD61).

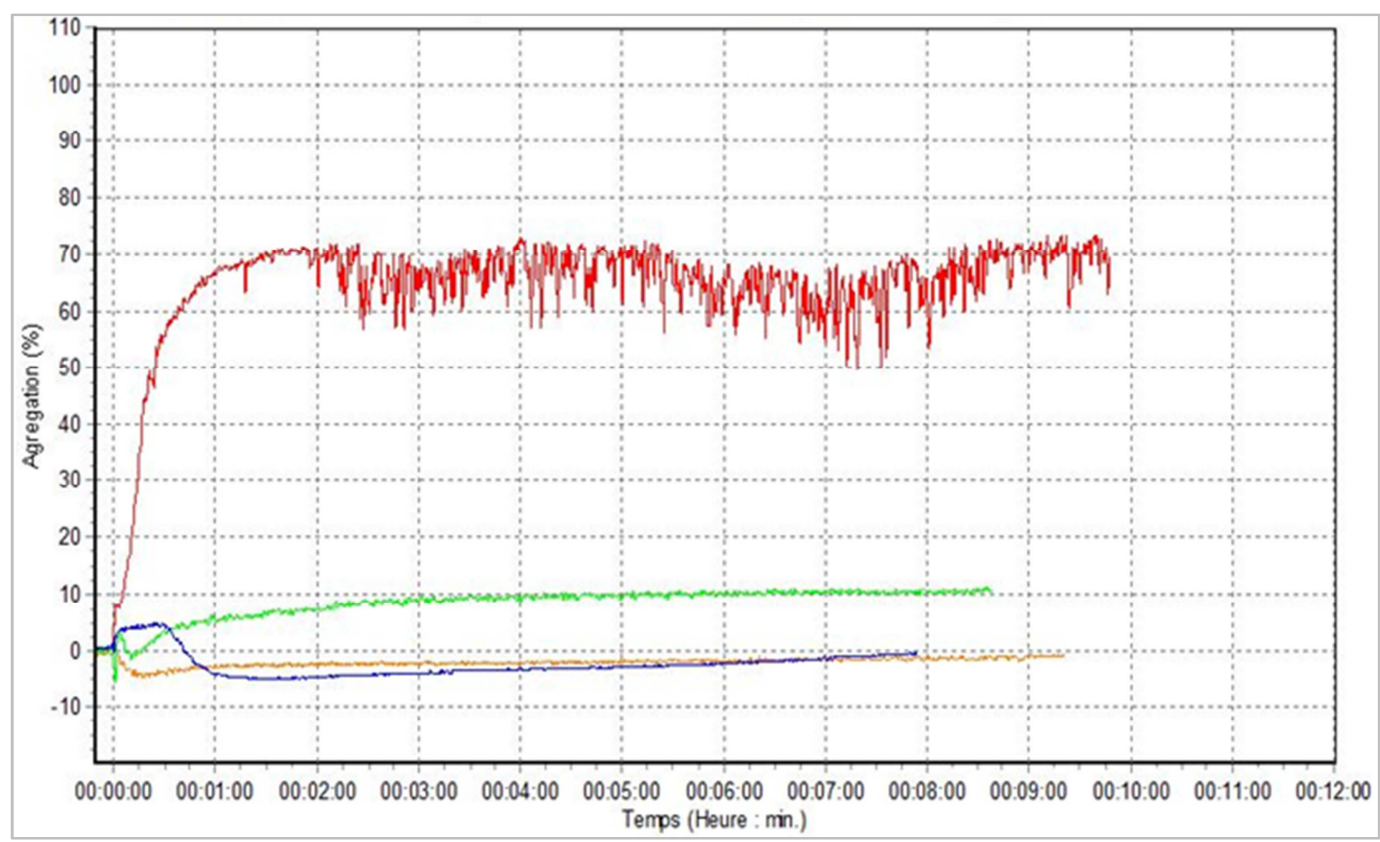

Orange: ADP Blue: arachidonic acid Green: Collagen Red: Ristocetin

Figure 1. Agregometric profile of the patient.

Table 1. Results of the hemogram of the patient.

\begin{tabular}{lll}
\hline Hemogram parameters & Patient & Normal values \\
\hline leukocytes $(109 / \mathrm{L})$ & 8,59 & 4 à 10 \\
Red cells $(1012 / \mathrm{L})$ & 5,10 & 4,2 à 5,2 \\
Haemoglobin $(\mathrm{g} / \mathrm{dL})$ & 12,5 & 12 à 16 \\
Hematocrit $(\%)$ & $38 \%$ & 37 à 47 \\
MCV $(\mathrm{fl})$ & 74,5 & 80 à 100 \\
MCH $(\mathrm{pg})$ & 24,5 & 27 à 32 \\
MCHC $(\mathrm{g} / \mathrm{dL})$ & 32,9 & 32 à 35 \\
Platelets $(109 / \mathrm{L})$ & 257 & 150 à 450 \\
MPV (fl) & 10,6 & 7 à 11 \\
\hline
\end{tabular}

MCV: MEAN CORPUSCULAR VOLUME

MCH: MEAN CORPUSCULAR HEMOGLOBIN

MCHC: MEAN CORPOSCULAR HEMOGLOBIN CONCENTRATION

MPV: MEAN PLATELET VOLUME

Table 2. Results of the patient's hemostasis assessment.

\begin{tabular}{lll}
\hline Hemostasis parameters & Patient & Normal values \\
\hline PT $(\%)$ & 95 & 70 à 100 \\
APTT $(\mathrm{sec})$ & 33 & 30 à 35 \\
FACTORVIII $(\%)$ & 150 & 50 à 15 \\
FACTOR XIII $(\%)$ & 79,4 & 50 à 140 \\
VWF -Ag $(\%)$ & 148 & 50 à 150 \\
VWF-RCo $(\%)$ & 116,8 & 50 à 150 \\
POT $(\mathrm{sec})$ & 278 & 80 à 160 \\
\hline
\end{tabular}

PT: Prothrombin time APTT: activated partial thromboplastin time VWF: von willebrand factor POT: platelet occlusion time
Table 3. Results of the patient's aggregometry tests.

\begin{tabular}{lll}
\hline Aggregometry parameters & Patient & Sample \\
\hline ADP (\%) & 1,88 & 81,61 \\
Arachidonic Acid (\%) & 9,15 & 88,11 \\
Collagen (\%) & 11,25 & 88,68 \\
Ristocetin (\%) & 65,37 & 78,58 \\
\hline
\end{tabular}

\section{Discussion}

Glanzmann thrombasthenia (GT) disease is the best known congenital thrombopathy. In this condition, transmission follows an autosomal recessive mode [4]. Although it is extremely rare worldwide it is found with relatively high frequency within populations that have a prevalence of consanguineous marriages where its frequency may rival that of much more common disorders such as Von Willebrand's Disease [5]. The four populations (all of which have a high frequency of intermarriage) in which it is most commonly seen are French Gypsies, Iraqi Jews, Jordanian Arabs, and South Indians $[6,7,8]$.

The disease is due to a qualitative or quantitative abnormality of GP IIb-IIIa, platelet abnormality responsible for a lack of platelet aggregation [1]. GP IIb-IIIa is located on the cytoplasmic membrane. By fixing fibrinogen, it allows the formation of interplatelet bridges at the base of the 
aggregation of activated platelets [9]. GP IIb-IIIa can bind its ligand (fibrinogen or other adhesive proteins) only after activation of the platelets and changes of its conformation. There are several types of Glanzmann thrombasthenia: types I, II and variants. Types I and II exhibit quantitative abnormalities of GP IIb-IIIa. In type I (this patient's case), the deficit is greater and GP IIb-IIIa is present only in the form of traces $(<5 \%)$. This is the most common form. In type II, the residual level of GP IIb-IIIa is of the order of 5 to $25 \%$. Variants are qualitative abnormalities of GP IIb-IIIa: this protein complex can not normally fix fibrinogen because of a structural anomaly of an active site [10].

The clinical expression of the disease is often early, sometimes from the first days of life, and is especially manifested in the mucous membranes (gingivorragies, purpura, epistaxis) [11].

The biological diagnosis of Glanzmann's disease is based on the demonstration of a deficiency of expression of GpIIbIIIa on the platelet surface. Glanzmann's thrombasthenia is characterized by normal platelet morphology and normal platelet count, prolonged bleeding time, absent or decreased clot retraction, and normal platelet aggregation in the presence of ristocetin. Platelet aggregation is absent in the presence of epinephrine, collagen, Arachidonic Acid, ADP, due to the dependence of these factors on fibrinogen attachment to the platelet for aggregation [12]. After exclusion of thrombocytopenia in patient, von Willebrand factor has been used to exclude previously suspected Willlebrand disease. The exploration of primary haemostasis was followed by the completion of the highly disturbed POT. This test is performed in the presence of a sample of whole blood subjected to high shear rates; the sample passes through a perforated and collagencoated membrane associated with a platelet activator (epinephrine or ADP) [13]. The POT corresponds to the time of occlusion of this orifice by the platelets. This parameter is dependent on the von Willebrand factor and platelets. However, platelet aggregation tests are abnormal. An absence of platelet aggregation regardless of the activator used is in favor of Glanzmann's disease; in aggregometry assays, platelet aggregation is provided by fibrinogen, which has the platelet GpIIbIIIa receptor. In this disease, only the ristocetin induces an aggregation but which is very disturbed: this agonist indeed activates the von Willebrand factor which in fact induces an agglutination of the platelets by binding to the GpIb but also to the residual GpIIbIIIa. Therefore, even though the exploration of platelet functions by aggregometry is a delicate technique, it is very useful for diagnosis [14].

The lack of expression of GpIIbIIIa is confirmed by three elements: 1) the study of platelet glycoproteins by flow cytometry shows that GpIIbIIIa is present with a low level, which evokes Glanzmann's disease type II, called moderate type; 2) the platelet count on a channel using an antiCD61 monoclonal antibody results in a rate in optical measurement; 3) electrophoresis of platelet membrane glycoproteins shows an absence of GpIIb and GpIIIa. The latter method is qualitative and involves the use of monoclonal antibodies different from those used in flow cytometry [15]. Treatment mainly includes local therapy, antifibrinolytics, and platelet transfusion. Recombinant factor VII is an acceptable alternative with excellent response rates. Bone marrow transplantation can be considered in patients with severe Glanzmann thrombasthenia who are unresponsive to conventional therapies. Undetected Glanzmann thrombasthenia can be life threatening so early diagnosis is a must to improve the prognosis [16].

\section{Conclusion}

Laboratory criteria for the diagnosis of this disorder in this child includes a normal platelet count, normal platelet morphology, prolonged bleeding time, Platelet aggregation absent or severely impaired in response adenosine diphosphate and other agonists, normal platelet agglutination with ristocetin, and normal plasma coagulation studies. Flow cytometry is also beneficial, since GT includes deficiency and / or dysfunction of glycoprotein receptors. In flow cytometric analysis, CD41 and CD61 levels were significantly reduced, which is consistent with the diagnosis of Glanzmann disease. Otherwise, the best way to diagnose GT in its entirety is through mutation analysis. Genomic DNA sequencing of the 45 exons comprising the $\alpha \operatorname{IIb} \beta 3$ unit, along with the splice sites of the ITGB3 and ITGA2B gene, should be investigated, and the established mutations should be confirmed with a second DNA sample analysis.

The development and availability of specialized tests and a close collaboration between clinician and biologist allowed the diagnosis of Glanzmann's disease in this child. Finally, Glanzmann thrombasthenia is associated with a very favorable prognosis when it is well managed.

\section{References}

[1] Gobbur RH, Varghese I. A rare case of Glanzmann Thrombasthenia. Int J Med Sci Public Health 2014; 3.

[2] Nurden P, Nurden A. Pathologies plaquettaires héréditaires. In: Sampol J, Arnoux D, Boutière B, et al. Manuel d'hémostase. Paris: Éditionsscientifiques et médicales Elsevier, 1995: 277 309.

[3] Malik U, Dutcher JP, Oleksowicz L. Acquired. Glanzmann'sthrombasthenia associated with Hodgkin's lymphoma: a case report and review of the literature. Cancer 1998; 82: 1764-8.

[4] French DL. The molecular genetics of Glanzmann's thrombasthenia. Platelets 1998; 9: 5-20.

[5] George JN, Caen JP, Nurden AT. Glanzmann's thrombasthenia: the spectrum of clinical disease. Blood. 1990; 75: 1383-95.

[6] Caen JP. Glanzmann's thrombasthenia. Baillieres Clin Haematol. 1989; 2: 609-625. 
[7] Caen JP. Glanzmann's thrombasthenia. Clin Haematol. 1972; 1: 383-92.

[8] Awidi AS. Increased incidence of Glanzmann's thrombasthenia in Jordan compared with Scandinavia. Scand J Haematol. 1983; 30: 218-22.

[9] Monrigal. C, Beurrier. P, Mercier. FJ, Boyer-Neumann. C, P. Gillard. Glanzmann's Thrombasthenia and pregnancy: a case and review of the literature. Annales Françaises d'Anesthésie et de Réanimation 22 (2003) 826-830.

[10] Stepanian. A et al. Diagnostic de la maladie de Glanzmann chez un patient de 66 ans. Annales de biologie cliniques (2001) 660-3.

[11] Jean-Louis Ntumba Mukendi, Souad Benkirane, Azlarab Masrar. Thrombasthénie de Glanzmann: à propos de 11 cas. Pan African Medical Journal. 2015; 21: 268.
[12] Christopher Sebastiano, Michael Bromberg, Karen Breen, Matthew T. Hurford. Glanzmann's thrombasthenia: report of a case and review of the literature. Int J Clin Exp Pathol 2010; 3(4): 443-447.

[13] Lecompte P. Exploration des fonctions plaquettaires en pratique clinique. Spectra Biologie 1999; 18: 21-6.

[14] Abdul Khalid, Tariq Baqai, Murtaza Bukhari Glanzmann`s Thrombosthenia: A rare cause of Recurrent Epistaxis. Int. j. pathol 2013; 11(2): 78-81

[15] Harrison P, Mackie I, Mumford A, Briggs C, Liesner R, Winter $\mathrm{M}$ et al. Guidelines for the laboratory investigation of heritable disorders of platelet function. Br J Haematol. 2011; 155(1): 30- 44 .

[16] Solh T, Botsford A, Solh M. Glanzmann's thrombasthenia: Pathogenesis, diagnosis, and current and emerging treatment options. J Blood Med. 2015; 6: 219-7. 